\title{
Statistical Analysis of Metal Chelating Activity of Centella asiatica and Erythroxylum cuneatum Using Response Surface Methodology
}

\author{
R. J. Mohd Salim, ${ }^{1,2}$ M. I. Adenan, ${ }^{1,2}$ A. Amid, ${ }^{3}$ M. H. Jauri, ${ }^{1}$ and A. S. Sued ${ }^{1}$ \\ ${ }^{1}$ Natural Product Division, Drug Discovery Centre (DDC), Forest Research Institute Malaysia (FRIM), Jalan Kepong, \\ Selangor Darul Ehsan, 52109 Kepong, Malaysia \\ ${ }^{2}$ Malaysian Institute of Pharmaceuticals and Nutraceuticals, Ministry of Science, Technology and Innovation, \\ USM, 10 Persiaran Bukit Jambul, 11900 Bukit Jambul, Malaysia \\ ${ }^{3}$ Department of Biotechnology Engineering, International Islamic University Malaysia, Gombak, \\ P.O. Box 10, 50728 Kuala Lumpur, Malaysia
}

Correspondence should be addressed to R. J. Mohd Salim; roshanjahn@frim.gov.my

Received 24 October 2012; Accepted 20 December 2012

Academic Editor: Triantafyllos Roukas

Copyright (C) 2013 R. J. Mohd Salim et al. This is an open access article distributed under the Creative Commons Attribution License, which permits unrestricted use, distribution, and reproduction in any medium, provided the original work is properly cited.

\begin{abstract}
The purpose of the study is to evaluate the relationship between the extraction parameters and the metal chelating activity of Centella asiatica (CA) and Erythroxylum cuneatum (EC). The response surface methodology was used to optimize the extraction parameters of methanolic extract of CA and EC with respect to the metal chelating activity. For CA, Run 17 gave optimum chelating activity with $\mathrm{IC}_{50}=0.93 \mathrm{mg} / \mathrm{mL}$ at an extraction temperature of $25^{\circ} \mathrm{C}$, speed of agitation at $200 \mathrm{rpm}$, ratio of plant material to solvent at $1 \mathrm{~g}: 45 \mathrm{~mL}$ and extraction time at 1.5 hour. As for EC, Run 13 with $60^{\circ} \mathrm{C}, 200 \mathrm{rpm}, 1 \mathrm{~g}: 35 \mathrm{~mL}$ and 1 hour had metal chelating activity at $\mathrm{IC}_{50}=0.3817 \mathrm{mg} / \mathrm{mL}$. Both optimized extracts were further partitioned using a solvent system to evaluate the fraction responsible for the chelating activity of the plants. The hexane fraction of CA showed potential activity with chelating activity at $\mathrm{IC}_{50}=0.090$ and the ethyl acetate fraction of EC had $\mathrm{IC}_{50}=0.120 \mathrm{mg} / \mathrm{mL}$. The study showed that the response surface methodology helped to reduce the extraction time, temperature and agitation and subsequently improve the chelating activity of the plants in comparison to the conventional method.
\end{abstract}

\section{Introduction}

The knowledge and practice of traditional medicine are universal amongst the respected ethnic groups in each country. In Malaysia the benefits of herbal medicine are being conveyed down from one generation to another. Latif et al. [1] state that there are four sources of traditional Malaysian medicine, namely, Malay village medicine (including Orang Asli medicine), Chinese medicine (introduced from China), Indian medicine (introduced from India), and other forms of traditional medicine (including those introduced by the Javanese, Sumatrans, Arabs, Persians, Europeans, etc.).

Centella asiatica (CA) also locally known as pegaga is a crawling plant usually growing wildly in a humid climate around the globe. Its wide medicinal benefits include wound healing, enhancing memory, treating mental weariness [2], anti-inflammatory property [3], anticancer activity [4], antilipid peroxidativity [5], and free radical scavenger [6].

Erythroxylum cuneatum forma cuneatum (Miq.) Kurz (EC) is a genus of tropical flowering plants in the family of Erythroxylaceae [7]. While CAs are being well studied for their various medicinal fortunes Erythroxylum cuneatum (EC) on the other hand has a very limited report on its medicinal value. In Terengganu, the leaves are pounded and applied on the forehead of women after miscarriage. In Bunguran, Indonesia leaves are reported to be used in Sajur (vegetable soup) [8]. It is used in Thai traditional medicine for antifever purposes as well as an anti-inflammatory agent [9]. 
TABLE 1: Parameters to be optimized using response surface methodology for CA and EC.

\begin{tabular}{lcc}
\hline & $\mathrm{CA}$ & EC \\
\hline $\begin{array}{l}\text { Temperature }\left({ }^{\circ} \mathrm{C}\right) \\
\left(X_{1}\right)\end{array}$ & $25,30,35$ & $55,60,65$ \\
$\begin{array}{l}\text { Speed }(\mathrm{rpm}) \\
\left(X_{2}\right)\end{array}$ & $100,150,200$ & $150,200,250$ \\
$\begin{array}{l}\text { Ratio }(\mathrm{g}: \mathrm{mL}) \\
\left(X_{3}\right)\end{array}$ & $1: 35,1: 40,1: 45$ & $1: 30,1: 35,1: 40$ \\
Time $(\mathrm{min})$ & $30,60,90$ & $30,60,90$ \\
$\left(X_{4}\right)$ & & \\
\hline
\end{tabular}

Neurodegenerative disease (ND) results from the deterioration of neurons which functionalize the intellectual and cognition ability of a human body [10]. Zecca et al. [11] reported that iron may engage in a mechanism involving many neurodegenerative disorders. It was deduced that, as the brain ages, iron accumulates in regions that are affected by Alzheimer and Parkinson diseases, diseases categorized under ND. Thus, it is the interest of the research to study the ability of CA and EC to chelate the metal iron and further optimize the extraction process of the plants with respect to their chelating activity.

The extraction of plant material for example bioactive compounds can be affected by more than one factor such as particle size, extraction solvent, temperature, and time [12]. Response surface methodology is a software tool used to study the interaction that may occur between variable factors [13]. This statistical experimental design is a powerful tool that enables the extraction process conducted effectively by verifying the effects of operational factors and their interactions [14]. The traditional empirical methods only study a single factor at a time and fail to acknowledge the interaction that they have between each other [15].

\section{Materials and Methods}

2.1. Materials. Centella asiatica (CA) was purchased from local market, Pasar Borong Selayang, Selangor, and Erythroxylum cuneatum (EC) was collected from FRIM's compound. Methanol was purchased from Fisher Scientific, ethanol from J. Kollin Corporation, Germany, and hexane, ethyl acetate, and n-butanol from Merck, USA. All chemicals and solvents used were of analytical grade. Iron (II) sulfate heptahydrate $\left(\mathrm{FeSO}_{4}\right)$ was a product of Aldrich, USA, 4,4' -[3-(2pyridinyl)-1,2,4-triazine-5,6-diyl]bis also known as ferrozine from Aldrich, USA.

\subsection{Methods}

2.2.1. Response Surface Methodology (RSM). RSM was used to optimize the conditions for extraction of CA and EC to give the optimum metal chelating activity. A face-centered cube design (FCD) in RSM consisting of 30 experimental runs including six replications at the center point was chosen to evaluate the combined effect of the independent variables. Three levels were adopted and coded to low, center, and high levels. The experiments were performed in random order to minimize the effects of unexplained variability in the observed responses due to systematic errors [15]. The independent variables were temperature $\left({ }^{\circ} \mathrm{C}\right)$, speed of rotation $(\mathrm{rpm})$, ratio of raw material to solvent $(\mathrm{g}: \mathrm{mL})$, and time of extraction (h), while the response is the metal chelating activity reported in $1 / \mathrm{IC}_{50}$. As the software was meant to display the response at maximum, the inverse $\mathrm{IC}_{50}$ $\left(1 / \mathrm{IC}_{50}\right)$ was reported in this study so that the $\mathrm{IC}_{50}$ will be displayed at its optimum activity.

The total of 30 runs designed by Design Expert by combining the parameters for extraction was shown in Table 1. The figures for each parameter were deduced from preliminary experiment. Each run was performed in triplicate.

2.2.2. Extraction Process. A constant weight of $2 \mathrm{~g}$ plants was used for all the 30 runs while adjusting accordingly to the ratio of methanol solvent that was needed in each run as outlined by Design Expert software. The plants were extracted in incubator shaker according to the combination parameters as given by each run. The extracts were then separated from the filtrate, and the methanol solvent was removed using rotary evaporator at $40^{\circ} \mathrm{C}$ and at a reduced pressure. The extracts from each run were then subjected to the metal chelating activity.

2.2.3. Metal Chelating Activity. The assay was initiated by adding $250 \mu \mathrm{L}$ of $2.5 \mathrm{mM} \mathrm{FeSO}_{4}$ to $500 \mu \mathrm{L}$ sample solutions; $\mathrm{CA}$ and EC crude extracts were prepared in a series of concentrations. This mixture was vortexed briefly for 10 seconds before adding $250 \mu \mathrm{L}$ of $6 \mathrm{mM}$ ferrozine. The mixture was vortexed again briefly for 10 seconds and allowed to equilibrate for $10 \mathrm{~min}$ at room temperature. The absorbance of the mixture (formation of the ferrous iron-ferrozine complex) was measured at $562 \mathrm{~nm}$ [16]. Sample solutions with appropriate dilutions were used as blanks. The ability of extracts to chelate ferrous ion was calculated relative to the control (consisting of iron and ferrozine only) using the following formula [17]:

$$
\begin{aligned}
& \text { Chelating effect } \% \\
& =\frac{(\text { Absorbance of control }- \text { Absorbance of sample })}{\text { Absorbance of control }} \\
& \quad \times 100 \text {. }
\end{aligned}
$$

2.2.4. Partitioning Process. The crude methanolic extracts were weighed to be $50 \mathrm{~g}$ and were suspended in water and then subjected to liquid-liquid partition by adding hexane, ethyl acetate, and n-butanol successively. The residual part that was suspended in water which was the water residue fraction [18] and the hexane, ethyl acetate, and n-butanol fraction were collected and subjected to metal chelating assay as described above. 
TABLE 2: Face centered, central composite design setting with the independent variables and their responses in CA.

\begin{tabular}{|c|c|c|c|c|c|c|}
\hline Run number & $X_{1}$ & $X_{2}$ & $X_{3}$ & $X_{4}$ & $\begin{array}{c}Y \\
1 / \mathrm{IC}_{50} \\
\end{array}$ & $\mathrm{IC}_{50}$ \\
\hline 1 & 30 & 150 & 40 & 60 & 1.72 & 0.5814 \\
\hline 2 & 30 & 150 & 40 & 60 & 1.429 & 0.6998 \\
\hline 3 & 35 & 100 & 35 & 30 & 5.2 & 0.1923 \\
\hline 4 & 30 & 150 & 40 & 60 & 1.55 & 0.6452 \\
\hline 5 & 30 & 150 & 40 & 90 & 1.96 & 0.5102 \\
\hline 6 & 35 & 200 & 35 & 30 & 2.4 & 0.4167 \\
\hline 7 & 30 & 150 & 40 & 60 & 1.3426 & 0.7448 \\
\hline 8 & 30 & 150 & 35 & 60 & 0.84 & 1.1905 \\
\hline 9 & 30 & 150 & 40 & 30 & 1.57 & 0.6369 \\
\hline 10 & 25 & 100 & 45 & 30 & 2.3 & 0.4348 \\
\hline 11 & 35 & 200 & 45 & 90 & 2.703 & 0.3700 \\
\hline 12 & 35 & 100 & 45 & 30 & 2.01 & 0.4975 \\
\hline 13 & 25 & 100 & 35 & 30 & 4.6 & 0.2174 \\
\hline 14 & 35 & 150 & 40 & 60 & 4.56 & 0.2193 \\
\hline 15 & 30 & 200 & 40 & 60 & 1.399 & 0.7148 \\
\hline 16 & 30 & 150 & 45 & 60 & 0.94 & 1.0638 \\
\hline 17 & 25 & 200 & 45 & 90 & 10.753 & 0.0930 \\
\hline 18 & 35 & 200 & 35 & 90 & 1.98 & 0.5051 \\
\hline 19 & 30 & 150 & 40 & 60 & 1.49 & 0.6711 \\
\hline 20 & 35 & 100 & 35 & 90 & 0.84 & 1.1905 \\
\hline 21 & 30 & 150 & 40 & 60 & 1.49 & 0.6711 \\
\hline 22 & 25 & 200 & 45 & 30 & 3 & 0.3333 \\
\hline 23 & 35 & 200 & 45 & 30 & 0.29 & 3.4483 \\
\hline 24 & 25 & 150 & 40 & 60 & 7.98 & 0.1253 \\
\hline 25 & 25 & 100 & 45 & 90 & 3.49 & 0.2865 \\
\hline 26 & 25 & 100 & 35 & 90 & 1.12 & 0.8929 \\
\hline 27 & 25 & 200 & 35 & 30 & 4.167 & 0.2400 \\
\hline 28 & 30 & 100 & 45 & 90 & 0.098 & 10.2041 \\
\hline 29 & 35 & 100 & 45 & 90 & 0.93 & 1.0753 \\
\hline 30 & 25 & 200 & 35 & 90 & 4.35 & 0.2299 \\
\hline
\end{tabular}

\section{Results and Discussion}

3.1. Optimization of Extraction with respect to Metal Chelating Activity. The optimum $1 / \mathrm{IC}_{50}$ value for CA (referred to in Table 2) was $10.753 \mathrm{mg} / \mathrm{mL}\left(\mathrm{IC}_{50}=0.093 \mathrm{mg} / \mathrm{mL}\right.$ ) obtained in the combined interaction of the independent parameter at Run 17 with $25^{\circ} \mathrm{C}, 200 \mathrm{rpm}, 1 \mathrm{~g}: 45 \mathrm{~mL}$ ratio, and for duration of 1.5 hour.

Table 3 summarized the experimental results for EC. The optimum $1 / \mathrm{IC}_{50}$ value of $2.6196 \mathrm{mg} / \mathrm{mL}\left(\mathrm{IC}_{50}=\right.$ $0.3817 \mathrm{mg} / \mathrm{mL}$ ) was obtained in Run 13 with temperature of $60^{\circ} \mathrm{C}$, agitation at $200 \mathrm{rpm}$, and ratio of raw material to solvent $1 \mathrm{~g}: 35 \mathrm{~mL}$ ratio for extraction duration of 1 hour.

3.2. Multiple Regression Analysis. The statistical model was developed by applying multiple regression analysis methods on using the experimental data for the metal chelating activity
TABLE 3: Face centered, central composite design setting with the independent variables and their responses in EC.

\begin{tabular}{|c|c|c|c|c|c|c|}
\hline Run number & $X_{1}$ & $X_{2}$ & $X_{3}$ & $X_{4}$ & $\begin{array}{c}Y \\
1 / \mathrm{IC}_{50} \\
\end{array}$ & $\mathrm{IC}_{50}$ \\
\hline 1 & 60 & 200 & 35 & 60 & 2.4 & 0.4167 \\
\hline 2 & 55 & 150 & 40 & 30 & 1.3 & 0.7692 \\
\hline 3 & 55 & 250 & 30 & 90 & 1.4 & 0.7143 \\
\hline 4 & 60 & 150 & 35 & 60 & 2.1 & 0.4762 \\
\hline 5 & 60 & 200 & 30 & 60 & 1.5 & 0.6667 \\
\hline 6 & 65 & 150 & 30 & 90 & 0.76 & 1.3158 \\
\hline 7 & 65 & 150 & 30 & 30 & 1.18 & 0.8475 \\
\hline 8 & 60 & 200 & 40 & 60 & 1.59 & 0.6289 \\
\hline 9 & 60 & 200 & 35 & 60 & 2.6 & 0.3846 \\
\hline 10 & 55 & 250 & 30 & 30 & 0.909 & 1.1001 \\
\hline 11 & 65 & 150 & 40 & 30 & 1.1 & 0.9091 \\
\hline 12 & 55 & 150 & 30 & 90 & 1.59 & 0.6289 \\
\hline 13 & 60 & 200 & 35 & 60 & 2.62 & 0.3817 \\
\hline 14 & 65 & 150 & 40 & 90 & 0.7 & 1.4286 \\
\hline 15 & 60 & 200 & 35 & 60 & 2.57 & 0.3891 \\
\hline 16 & 55 & 250 & 40 & 90 & 1.39 & 0.7194 \\
\hline 17 & 60 & 200 & 35 & 90 & 1.57 & 0.6369 \\
\hline 18 & 65 & 200 & 35 & 60 & 1.68 & 0.5952 \\
\hline 19 & 60 & 200 & 35 & 60 & 2.56 & 0.3906 \\
\hline 20 & 55 & 200 & 35 & 60 & 1.89 & 0.5291 \\
\hline 21 & 60 & 200 & 35 & 30 & 1.55 & 0.6452 \\
\hline 22 & 60 & 250 & 35 & 60 & 2.1 & 0.4762 \\
\hline 23 & 65 & 250 & 30 & 90 & 0.833 & 1.2005 \\
\hline 24 & 65 & 250 & 30 & 30 & 1.25 & 0.8000 \\
\hline 25 & 60 & 200 & 35 & 60 & 2.56 & 0.3906 \\
\hline 26 & 55 & 150 & 30 & 30 & 1.28 & 0.7813 \\
\hline 27 & 65 & 250 & 40 & 30 & 1.36 & 0.7353 \\
\hline 28 & 55 & 150 & 40 & 90 & 1.66 & 0.6024 \\
\hline 29 & 65 & 250 & 40 & 90 & 0.906 & 1.1038 \\
\hline 30 & 55 & 250 & 40 & 30 & 1.1 & 0.9091 \\
\hline
\end{tabular}

which is given in (2) for CA and in (3) for EC. The response function $(y)$ measured the $1 / \mathrm{IC}_{50}$ value of the metal chelating activity of the crude extracts CA and EC. This value was related to the variables $(A, B, C, D)$ by a second-degree polynomial using (2) and (3) which is displayed in terms of coded factors. The coefficients of the polynomial were represented by a constant term, $A, B, C$, and $D$ (linear effects), $A^{2}, B^{2}, C^{2}$, and $D^{2}$ (quadratic effects), and $A B$, $A C, A D, B C, B D$, and $C D$ (interaction effects). The analysis of variance (ANOVA) tables were generated, and the effect and regression coefficients of individual linear, quadratic, and interaction terms were determined. The significances of all terms in the polynomial were judged statistically by computing the $F$-value at a probability $(P)$ of $0.001,0.01$, or 0.05. In this case $A, B, A^{2}, B^{2}, C^{2}, A B, A C, A D, B C, B D$, and $C D$ are significant model terms. On the other hand, values greater than 0.1000 indicate that the model terms are 
TABLE 4: Fit statistics for the response of $1 / \mathrm{IC}_{50}$ value of CA.

\begin{tabular}{lccc}
\hline Standard deviation & 0.14 & $R$-squared & 0.9746 \\
Mean & 1.49 & Adjusted $R$-squared & 0.9509 \\
C.V. & 9.40 & Predicted $R$-squared & 0.8608 \\
PRESS & 1.62 & Adequate precision & 27.272 \\
\hline
\end{tabular}

TABLE 5: Fit statistics for the response of $1 / \mathrm{IC}_{50}$ value of EC.

\begin{tabular}{lccc}
\hline Standard deviation & 0.26 & $R$-squared & 0.9028 \\
Mean & 1.60 & Adjusted $R$-squared & 0.8120 \\
C.V. & 16.12 & Predicted $R$-squared & 0.7243 \\
PRESS & 2.83 & Adequate precision & 9.404 \\
\hline
\end{tabular}

not significant. The regression coefficients were then used to make statistical calculation to generate contour maps from the regression models:

$$
\begin{aligned}
\mathrm{IC}_{50}= & +1.79-1.16 * X_{1}+0.58 * X_{2}+0.051 * X_{3} \\
& +0.14 * X_{4}+4.20 * X_{1}^{2}-1.32 * X_{2}^{2} \\
& -1.18 * X_{3}^{2} 0.31 * X_{4}^{2}-0.77 * X_{1} * X_{2} \\
& -0.61 * X_{1} * X_{3}-0.57 * X_{1} * X_{4} \\
& +0.43 * X_{2} * X_{3}+1.10 * X_{2} * X_{4} \\
& +1.15 * X_{3} * X_{4}, \\
\mathrm{IC}_{50}= & +2.29-0.15 * X_{1}-0.023 * X_{2}+0.022 * X_{3} \\
& -0.012 * X_{4}-0.25 * X_{2}^{2}+0.063 * X_{2}^{2} \\
& +0.022 * X_{3}^{2}-0.48 * X_{4}^{2}+0.10 * X_{1} * X_{2} \\
& -0.014 * X_{1} * X_{3}-0.20 * X_{1} * X_{4} \\
& +0.026 * X_{2} * X_{3}+3.750 \exp -003 * X_{2} * X_{4} \\
& -0.010 * X_{3} * X_{4} .
\end{aligned}
$$

3.3. Fit Statistics for the Response. Some characteristics of the constructed model can be explained by details in Table 4 and Table 5. The statistical analysis indicates that the proposed model was adequate, possessing no significant lack of fit and with satisfactory values of the $R$-squared. The quality of fit of the polynomial model equation was expressed by the coefficient of determination $\left(R^{2}\right.$, adjusted $R^{2}$, and adequate precision). $R^{2}$ is a measure of the amount of variation around the mean explained by the model and equal to 0.9569 (CA) and 0.9028 (EC). The closer the value of $R$-squared is to the unity, the better the empirical model fits the actual data. The smaller the value of $R$-squared is, the less relevant the dependent variables in the model have to explain the behavior variation [18] and [19]. The adjusted $-R^{2}$ is adjusted for the number of terms in the model. It decreases as the number of terms in the model increases, if those additional terms do not add value to the model. Adequate precision is a signalto-noise ratio. It compares the range of the predicted values at the design points to the average prediction error. Ratios greater than four indicate adequate model discrimination. As for CA it was 21.064 whereas for EC it was 9.404. The standard deviation of 0.66 (CA) and 0.26 (EC) indicates that the model designed was acceptable with a minimum deviation. Coefficient of variation (C.V.) is the standard deviation expressed as a percentage of the mean which is 25.34\% (CA) and 16.12 (EC). CV describes the extent to which the data were dispersed. The small values of $\mathrm{CV}$ give better reproducibility. In general, a high $\mathrm{CV}$ indicates that variation in the mean value is high and does not satisfactorily develop an adequate response model [20].

The predicted residual error sum of squares (PRESS) is a measure of model fitness to each point in the design which gave an amount of 46.29 (CA) and 16.12 (EC).

\section{Conclusion}

The metal chelating activity of CA and EC was optimized using statistical analysis to improve the chelating activity of the both plants by varying the parameters for the extraction. It shows that the extraction parameters had been optimized $\left(\mathrm{IC}_{50}=0.093 \mathrm{mg} / \mathrm{mL}\right.$ at extraction temperature of $25^{\circ} \mathrm{C}$, speed of agitation at $200 \mathrm{rpm}$, ratio of plant material to solvent at $1 \mathrm{~g}$ : $45 \mathrm{~mL}$, and extraction time at 1.5 hour). As for EC, Run 13 with extraction temperature at $60^{\circ} \mathrm{C}$, speed of agitation at $200 \mathrm{rpm}$, ratio of plant material to solvent at $1 \mathrm{~g}: 35 \mathrm{~mL}$, and extraction time at 1 hour had metal chelating activity at $\mathrm{IC}_{50}=0.3817 \mathrm{mg} / \mathrm{mL}$.

\section{Acknowledgment}

The authors would like to thank FRIM and MOSTI for providing fund for the research.

\section{References}

[1] M. Latiff, "Genetic resources of medicinal plants in Malaysia," in Genetic Resources of Under-Utilised Plants in Malaysia: Proceedings of the National Workshop on Plant Genetic Resources Held in Subang Jaya, Malaysia, A. H. Zakri, Ed., Malaysian National Committee on Plant Genetic Resources, Kuala Lumpur, Malaysia, 1989.

[2] M. T. Thomas, R. Kurup, A. J. Johnson et al., "Elite genotypes/chemotypes, with high contents of madecassoside and asiaticoside, from sixty accessions of Centella asiatica of south India and the Andaman Islands: for cultivation and utility in cosmetic and herbal drug applications," Industrial Crops and Products, vol. 32, no. 3, pp. 545-550, 2010.

[3] L. Suguna, P. Sivakumar, and G. Chandrakasan, "Effects of Centella asiatica extract on dermal wound healing in rats," Indian Journal of Experimental Biology, vol. 34, no. 12, pp. 12081211, 1996.

[4] T. D. Babu, G. Kuttan, and J. Padikkala, "Cytotoxic and antitumour properties of certain taxa of Umbelliferae with special reference to Centella asiatica (L.) Urban," Journal of Ethnopharmacology, vol. 48, no. 1, pp. 53-57, 1995.

[5] S. S. Katare and M. S. Ganachari, "Effect of Centella asiatica on hypoxia induced convulsions and lithium-pilocarpine induced 
status epilepticus and antilipid peroxidation activity," Indian Journal of Pharmacology, vol. 33, article 128, 2001.

[6] G. Jayashree, G. K. Muraleedhara, S. Sudarslal, and V. B. Jacob, "Anti-oxidant activity of Centella asiatica on lymphoma-bearing mice," Fitoterapia, vol. 74, no. 5, pp. 431-434, 2003.

[7] R. J. M. Salim, Optimisation of extraction of Centella asiatica and Erythroxylum cuneatum and their evaluation as a neuroprotective agent [Master's thesis], International Islamic University Malaysia, Selangor, Malaysia, 2010.

[8] A. S. Sued, Kesan ekstrak Centella asiatica Linnaeus dan Erythroxylum cuneatumForma Cuneatum (Miquel) Kurz ke atas symptom tarikan pada tikus ketagihan morfina dan protein serum mereka [Master's thesis], Universiti Kebangsaan Malaysia, Selangor, Malaysia, 2009.

[9] T. Kanchanapoom, A. Sirikatitham, H. Otsuka, and S. Ruchirawat, "Cuneatoside, a new megastigmane diglycoside from Erythroxylum cuneatum Blume," Journal of Asian Natural Products Research, vol. 8, no. 8, pp. 747-751, 2006.

[10] J. F. Emard, J. P. Thouez, and D. Gauvreau, "Neurodecgnerative diseases and risk factors: a literature review," Social Science and Medicine, vol. 40, no. 6, pp. 847-858, 1995.

[11] L. Zecca, M. B. H. Youdim, P. Riederer, J. R. Connor, and R. R. Crichton, "Iron, brain ageing and neurodegenerative disorders," Nature Reviews Neuroscience, vol. 5, no. 11, pp. 863-873, 2004.

[12] B. Yang, X. Liu, and Y. Gao, "Extraction optimization of bioactive compounds (crocin, geniposide and total phenolic compounds) from Gardenia (Gardenia jasminoides Ellis) fruits with response surface methodology," Innovative Food Science and Emerging Technologies, vol. 10, no. 4, pp. 610-615, 2009.

[13] J. H. Kwon, J. M. R. Belanger, and J. R. J. Pare, "Optimization of microwave assisted extraction (MAP) for ginseng components by response surface methodology," Journal of Agricultural and Food Chemistry, vol. 51, pp. 1807-1810, 2003.

[14] W. Huang, Z. Li, H. Niu, D. Li, and J. Zhang, "Optimization of operating parameters for supercritical carbon dioxide extraction of lycopene by response surface methodology," Journal of Food Engineering, vol. 89, no. 3, pp. 298-302, 2008.

[15] C. S. Ku and S. P. Mun, "Optimization of the extraction of anthocyanin from Bokbunja (Rubus coreanus Miq.) marc produced during traditional wine processing and characterization of the extracts," Bioresource Technology, vol. 99, no. 17, pp. 8325-8330, 2008.

[16] T. C. P. Dinis, V. M. C. Madeira, and L. M. Almeida, "Action of phenolic derivatives (acetaminophen, salicylate, and 5aminosalicylate) as inhibitors of membrane lipid peroxidation and as peroxyl radical scavengers," Archives of Biochemistry and Biophysics, vol. 315, no. 1, pp. 161-169, 1994.

[17] Y. Wu, S. W. Cui, J. Tang, and X. Gu, "Optimization of extraction process of crude polysaccharides from boat-fruited sterculia seeds by response surface methodology," Food Chemistry, vol. 105, no. 4, pp. 1599-1605, 2007.

[18] T. Satake, K. Kamiya, Y. An, T. Oishi, and J. Yamamoto, "The anti-thrombotic active constituents from Centella asiatica," Biological and Pharmaceutical Bulletin, vol. 30, no. 5, pp. 935940, 2007.

[19] T. M. Little and F. J. Hills, Agricultural Experimentation Design and Analysis, John Wiley, New York, NY, USA, 1978.

[20] W. W. Daniel, Biostatistics: A Foundation for Analysis in the Health Sciences, vol. 503, Wiley, New York, NY, USA, 5th edition, 1991. 

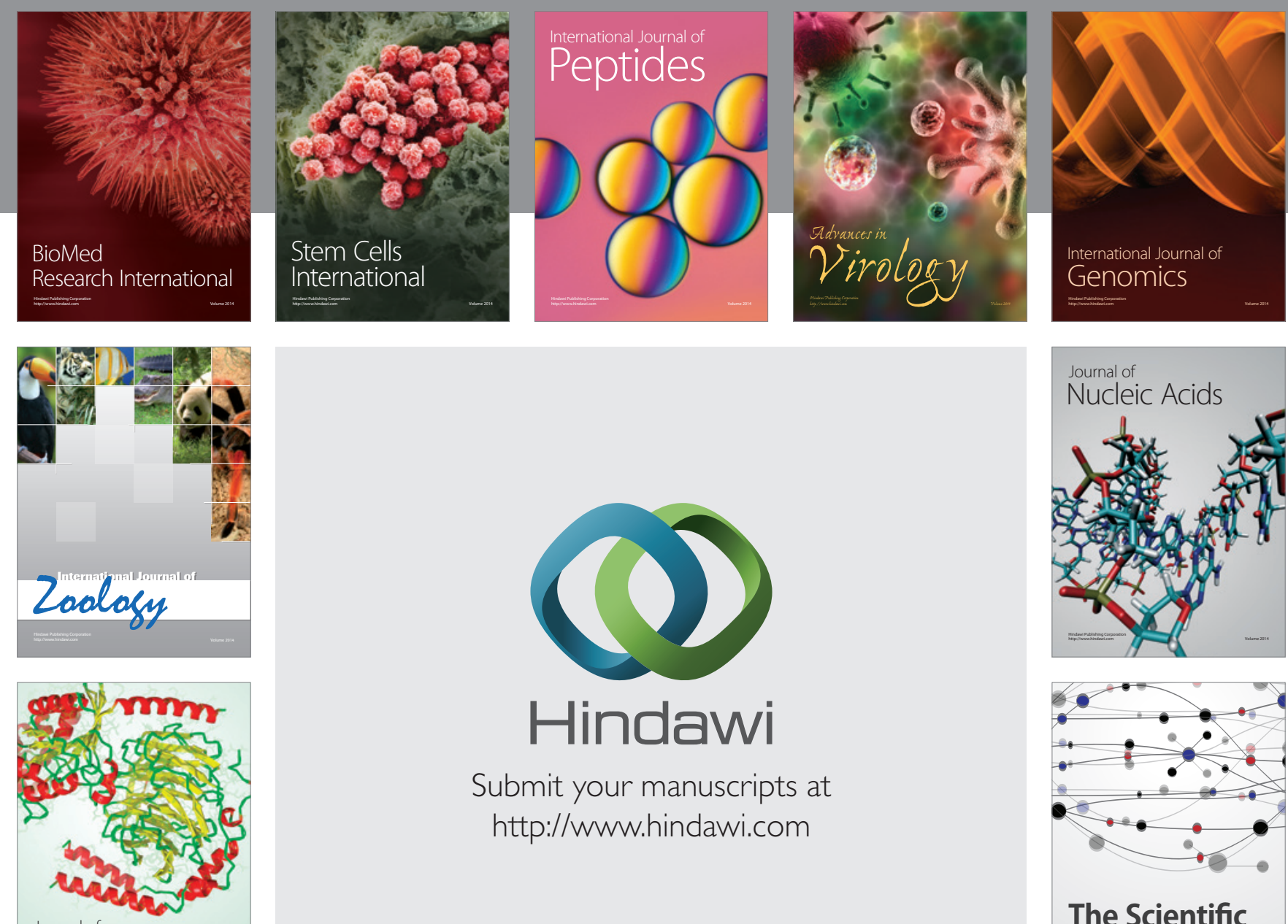

Submit your manuscripts at

http://www.hindawi.com

Journal of
Signal Transduction
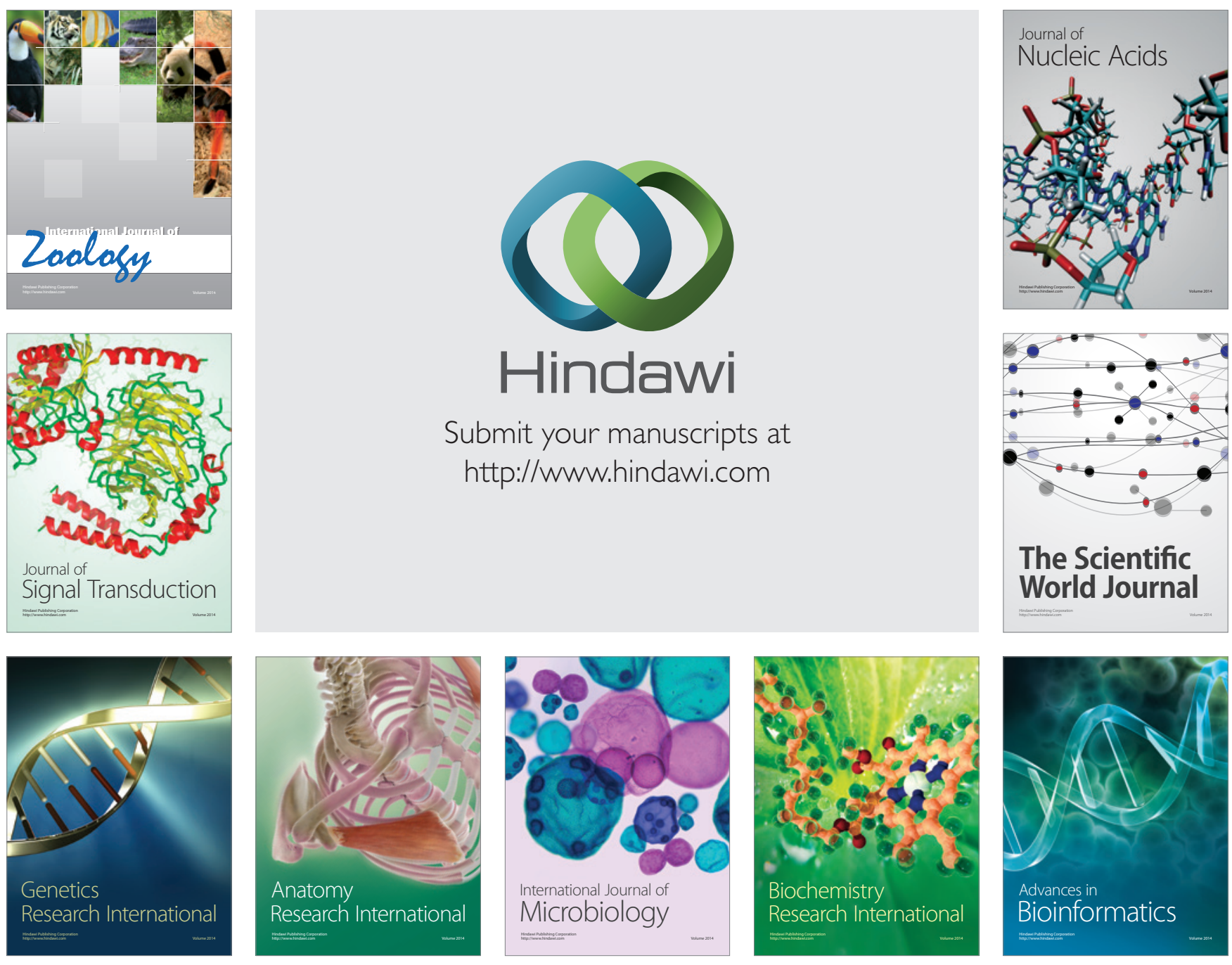

The Scientific World Journal
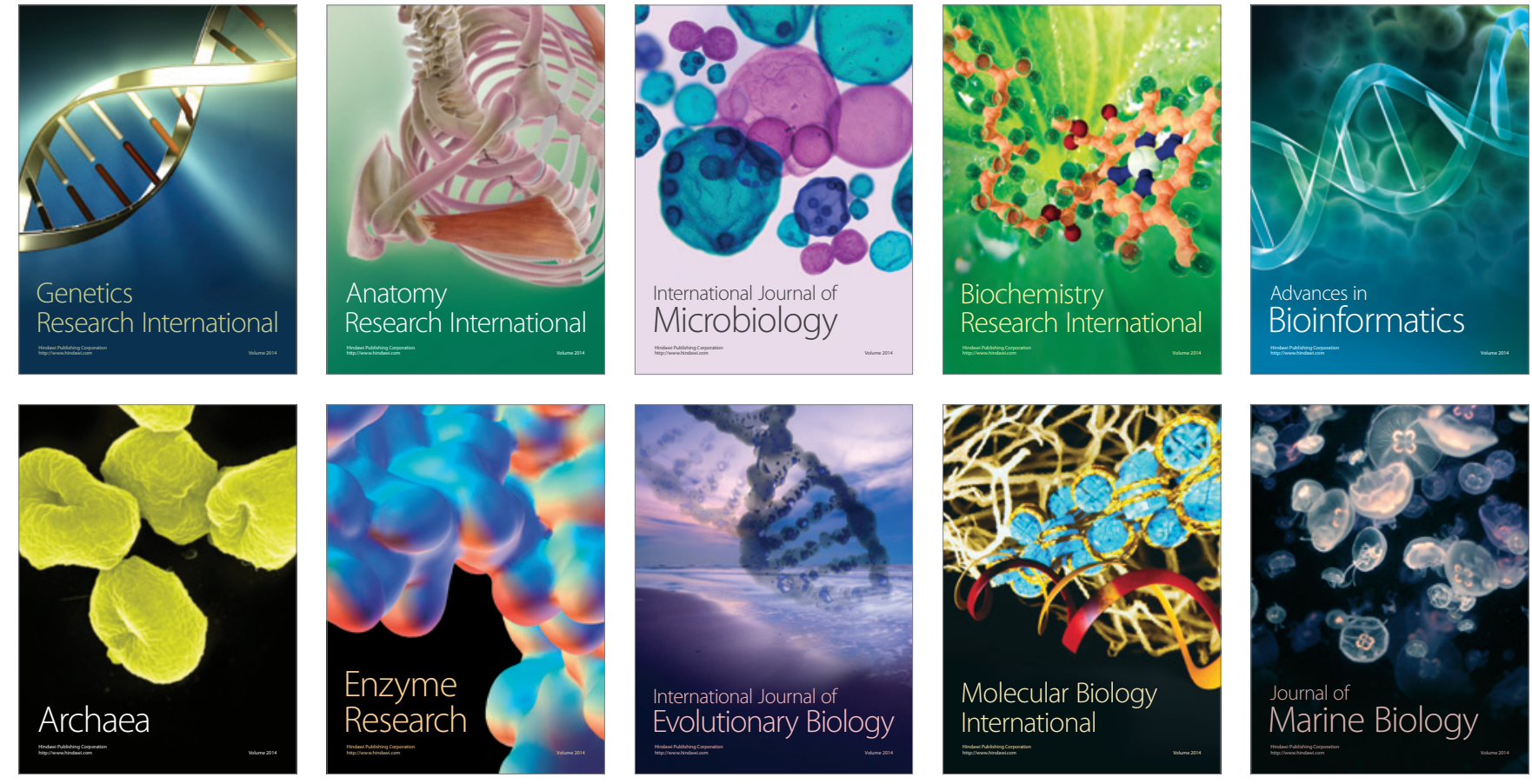